\title{
Nucleolar protein PinX1p regulates telomerase by sequestering its protein catalytic subunit in an inactive complex lacking telomerase RNA
}

\author{
Jue Lin and Elizabeth H. Blackburn ${ }^{1}$ \\ Department of Biochemistry and Biophysics, University of California, San Francisco, \\ San Francisco, California 94143-2200, USA
}

\begin{abstract}
Human TRF1-binding protein PinX1 inhibits telomerase activity. Here we report that overexpression of yeast PinX1p (yPinX1p) results in shortened telomeres and decreased in vitro telomerase activity. yPinX1p coimmunoprecipitated with yeast telomerase protein Est2p even in cells lacking the telomerase RNA TLC1, or the telomerase-associated proteins Est1p and Est3p. Est2p regions required for binding to yPinX1p or TLC1 were similar. Furthermore, we found two distinct Est2p complexes exist, containing either yPinX1p or TLC1. Levels of Est2p-yPinX1p complex increased when TLC1 was deleted and decreased when TLC1 was overexpressed. Hence, we propose that $\mathrm{YPinX1p}$ regulates telomerase by sequestering its protein catalytic subunit in an inactive complex lacking telomerase RNA.
\end{abstract}

[Keywords: Telomerase regulation; telomerase sequestration; alternative telomerase complex; PinX1-telomerase protein complex]

Supplemental material is available at http://www.genesdev.org.

Received November 24, 2003; revised version accepted December 30, 2003.

Telomerase is required for complete replication of chromosomal ends and for genome stability (Blackburn 2000). Without telomerase, loss of telomeric sequence due to incomplete DNA replication and nuclease action leads to telomere shortening and eventual cellular senescence. The core telomerase enzyme is minimally composed of two subunits: the reverse transcriptase protein TERT (Est2p in Saccharomyces cerevisiae) and the template-containing RNA component TER (TLC1 in S. cerevisiae). These two components from various organisms can reconstitute in vitro enzymatic activity (Weinrich et al. 1997; Beattie et al. 1998; Licht and Collins 1999). Although additional proteins are required for telomerase to act in vivo (Blackburn 2000; Blasco 2002), little is known about other factors that may regulate telomerase activity.

Telomerase action on telomeres is regulated during the cell cycle and developmentally. Studies of telomerase in $S$. cerevisiae demonstrated that the enzyme is most active on shortened telomeres in late $S$ phase or $\mathrm{G}_{2} / \mathrm{M}$ phase, the time when telomeres are replicated (Diede and Gottschling 1999; Marcand et al. 2000). In the

${ }^{1}$ Corresponding author.

E-MAIL telomer@itsa.ucsf.edu; FAX (415) 514-2913.

Article published online ahead of print. Article and publication date are at http://www.genesdev.org/cgi/doi/10.1101/gad.1171804. ciliate Euplotes crassus, telomerase complexes with distinct biochemical and structural properties can be purified during different developmental stages (Greene and Shippen 1998). Telomerase activity is constitutively expressed in human germ-line and other dividing cells, but is diminished in many normal somatic cells. The vast majority of primary tumors and tumor-derived cell lines have robust telomerase activity, whereas inhibition of telomerase or interference with its action limits the growth of human cancer cells (Blasco and Hahn 2003). Thus, stimulation of telomerase activity in cancer cells is a key step toward tumorigenesis.

Telomerase activity can be regulated at multiple levels. In yeast, although Est2p protein and TLC1 RNA are present throughout the whole cell cycle, addition of telomeric DNA is restricted to late $S$ phase or $G_{2} / M$ phase. It was proposed that telomerase is only activated during these phases of the cell cycle (Marcand et al. 2000; Taggart et al. 2002; Taggart and Zakian 2003). A similar model was suggested for human telomerase (Loayza and De Lange 2003). TERT expression can be regulated both transcriptionally and posttranscriptionally. In E. crassus, three different TERT variants with different expression profiles have been found, and a switch between different catalytic subunits was proposed to occur during development (Karamysheva et al. 2003). Although hTERT transcription is low in many human tissues, it is com- 
monly reactivated in tumors (Blasco and Hahn 2003). In addition, posttranslational phosphorylation of hTERT has been observed during T-cell activation (Liu et al. 2001). Translocation of telomerase between cytoplasm and nucleus, and between nucleolus and nucleoplasm, have also been proposed as activity regulation mechanisms (Seimiya et al. 2000; Liu et al. 2001; Wong et al. 2002).

Sequestration into alternative complexes is a known mechanism for regulating the function of many proteins. For example, NF-кB, a protein important for inflammatory, immune, and antiapoptotic responses in mammals (Ghosh et al. 1998), is sequestered in the cytoplasm by binding to a family of inhibitory proteins, IкBs. NF- $\kappa$ B is released upon ubiquitination of IкBs and subsequently translocates to the nucleus to function as a transcriptional activator (Baldwin 1996). Similarly, separase, the protease that cleaves the chromosomal cohesin complex, is regulated by its binding partner securin, which directly inhibits the proteolytic activity of separase by preventing separase from binding its substrates (Concannon et al. 2001; Hornig et al. 2002; Waizenegger et al. 2002).

The possibility that telomerase might be regulated by sequestering TERT in an alternative complex has not been previously explored. Here we report evidence for a novel molecular mechanism for telomerase regulation, in which the yeast telomerase catalytic protein can form an inactive complex that contains nucleolar protein yPinX1p but not the essential RNA component of the telomerase enzyme. Human PinX1p, initially identified as a protein that interacts with the telomeric protein TRF1/Pin2, was previously reported to bind to hTERT and directly inhibit telomerase activity in in vitro assays (Zhou and Lu 2001). Depletion of hPinX1p increases tumorigenicity in a mouse host, suggesting that hPinX1p might be a tumor suppressor (Zhou and Lu 2001). However, the molecular mechanisms of PinX1p action were unknown.

The yeast homolog of PinX1p (also called Gnolp, Gpatch nucleolar protein $\underline{1}$ ) is an essential protein in-

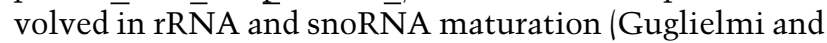
Werner 2002). yPINX1 deletion cells have poor growth with a doubling time of $\sim 4.9 \mathrm{~h}$ compared with $1.5 \mathrm{~h}$ for wild-type cells (Guglielmi and Werner 2002). Guglielmi and Werner (2002) previously concluded, because telomeres in $\Delta y p i n X 1$ cells were slightly shorter than those in wild-type cells, that yPinX1p is not a telomerase inhibitor, unlike its human counterpart.

Here we show that overexpression of yPinX1p causes telomere shortening and decreased in vitro telomerase enzymatic activity. We provide evidence that the same central region of Est $2 p$ is required for binding of $y$ PinX1p or TLC1 RNA. A new in vivo Est2p complex, containing yPinX1p but not TLC1, was detected. The level of this Est2p-yPinX1p complex was increased in a $\Delta t l c 1$ strain and decreased upon TLC1 overexpression, indicating that yPinX1p competes with TLC1 for binding to Est2p. Taken together, we propose that PinX1p inhibits telomerase activity by sequestering the protein reverse transcriptase subunit into an inactive complex.

\section{Results}

Overexpression of yeast PinX1p shortens telomeres and decreases in vitro telomerase activity

To determine whether yeast PINX1 plays a role in telomere maintenance, we assayed the effects of $y$ PinX $1 p$ overexpression on telomere length. We cloned yPINX1 under the GAL1 promoter on a CEN/ARS plasmid. To determine the yPinX1p overexpression level, we tagged both the endogenous $y$ PINX1 gene and the GalPinX1 plasmid with 13 myc tags at the $C$ termini and compared the expression levels by Western blotting using an antimyc antibody. We found that when induced with galactose, yPinX1p was expressed approximately fourfold over its endogenous level (data not shown). Wild-type yeast cells, transformed with the $y P I N X 1$ overexpression plasmid or the control vector lacking the yPINX1 ORF, were grown under noninducing (glucose) or inducing (galactose) conditions, and telomere length was examined by Southern blotting. Telomeres in cells overexpressing yPinX1p were $\sim 70-80$ bp shorter than telomeres in controls cells (Fig. 1A, cf. V and P lanes). This shortening was not caused by a difference in the medium, because telomere length was identical in control cells grown in glucose or galactose medium (Fig. 1A cf., V lanes + and -). Telomere shortening was visible by 25 generations of growth on galactose (data not shown), and became more pronounced at the third streak, as shown in Figure 1A. Therefore, these data suggested a role for yPINX1 in telomere maintenance.

Telomere shortening upon yPINX1 overexpression could potentially result from decreased telomerase enzymatic activity per se, or from decreased telomerase action caused by structural and/or conformational changes at the telomeres. In yeast, telomere length is negatively regulated by Raplp and its binding partners Riflp and Rif2p. It was proposed that Raplp binds to telomeric DNA in a sequence-specific manner and recruits Rif1p, Rif2p, and other proteins to form a higher-order complex that limits access of telomerase to telomeres (Marcand et al. 1997). Telomeres become elongated when RIF1 or RIF2 is deleted (Hardy et al. 1992; Wotton and Shore 1997). To determine whether the telomere shortening by yPinX1p overexpression requires Riflp or Rif $2 \mathrm{p}$, we overexpressed yPinX1p in RIF1 or RIF2 deletion strains. If the telomere shortening effect of overexpression of yPinX1p is mediated through the Rif proteins, such shortening should be alleviated by deletion of Rif1p or Rif2p. However, in both $\Delta$ rif1 and $\Delta$ rif2 strains, significant telomere shortening was still observed upon yPinX1p overexpression (Fig. 1B). Hence, telomere shortening caused by overexpression of $y$ PinX $1 p$ is not solely dependent on either Rif $1 p$ or Rif $2 p$, although some role for either protein cannot be completely excluded.

We overexpressed telomerase protein subunit Est2p in addition to yPinX1p. Expression of Est2p under its endogenous promoter from a high-copy $2 \mu$ plasmid caused slight lengthening of telomeres (Fig. 1C, left part, cf. V and $\mathrm{P}+\mathrm{E}$ lanes when PinX1p was not overexpressed). 
PinX1 sequesters telomerase reverse transcriptase

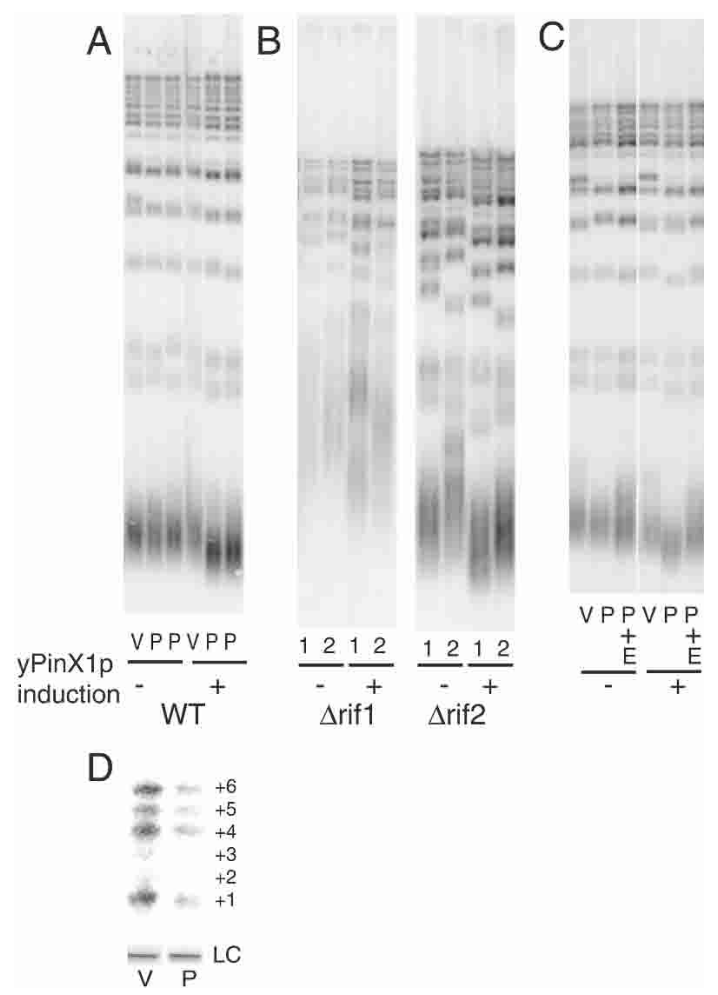

Figure 1. Overexpression of yPinX1p leads to shortened telomeres and decreased in vitro telomerase activity. $(A)$ Southern blot of telomeres in wild-type cells (strain BY4705) overexpressing yPinX1p. (B) $\Delta$ rif1 (yEHB0234) and $\Delta$ rif2 (yEHB0235) strains overexpressing yPinX1p. (C) Wild-type cells overexpressing both yPinX1p and Est2p. (V) Vector plasmid; (P) yPinX1 overexpression plasmid with Gal promoter (pRS316GalPinX1); (E) Est2myc overexpression plasmid (pRS424Est2myc); (-) cells grown in glucose medium; $(+)$ cells grown in galactose medium. In $B$, results from two independent transformants with pRS316GalPinX1 are shown. (D) In vitro telomerase activity assay. (LC) Loading control. A $\gamma^{32}$ P-ATP-labeled oligonucleotide was added to the assay as the loading control. Products with 1-6 nt added to the primer are indicated.

Interestingly, telomere length was restored to wild-type upon overexpression of both Est $2 \mathrm{p}$ and yPinX1p together, consistent with the possibility that yPinX1p influences telomerase enzymatic activity directly (Fig. 1C, cf. $\mathrm{P}$ and $\mathrm{P}+\mathrm{E}$ lanes under yPinX1p overexpression conditions). This possibility was confirmed by comparison of in vitro telomerase activity in extracts of cells overexpressing yPinX1p to those containing only the vector control. Telomerase was partially purified by DEAE chromatography as previously described /Cohn and Blackburn 1995). To make quantitative comparisons, the TLC1 peak fraction was used, and each assay contained equal amounts of TLC1 RNA. Cells overexpressing yPinX1p had a decreased in vitro activity $133 \%$ of the control, after normalization and correction for background signal; see Fig. 1D). Taken together, these results show that overexpression of yPinX1p decreases telomerase enzyme activity and telomere length in yeast cells.

\section{yPinX1p associates with Est $2 p$ in vivo}

Because yPinX1p is involved in rRNA and snoRNA processing, we first tested whether overexpression of yPinX1p alters the levels of two RNAs involved in telomerase activity: TLC1 RNA and EST2 mRNA. Induction of yPinX1p overexpression did not change either the TLC1 RNA or the EST2 mRNA levels (Supplemental Fig. S1A). Furthermore, Western blotting analysis of Est2p tagged with 13 tandem myc epitopes (Est2p-myc) expressed from its endogenous locus showed no change in the total Est2p protein level upon yPinX1p overexpression (Supplemental Fig. S1B). However, despite the same levels of total Est2p-myc in whole cell extracts, we found that the amount of Est2p-myc immunoprecipitable with anti-myc antibody was significantly decreased in the cells overexpressing yPinX1p, compared with the vector control cells (Supplemental Fig. S1C). These results indicated that even though yPinX1p overexpression does not alter the total levels of Est2p, the myc epitopes on Est $2 p$ became less accessible to antibody binding.

Human PinX1p has been shown to interact with hTERT both in vitro and in vivo (Zhou and Lu 2001). We therefore examined whether yPinX1p is associated with Est2p in vivo by coimmunoprecipitation. yPinX1p was tagged with the TAP tag (Puig et al. 2001), and Est2p was tagged with the 13-myc tag in strain yEHB4114, with both proteins expressed from their endogenous chromosomal loci. Strain yEHB4008, containing myc-tagged Est2p, but untagged yPinX1p, was used as the control. Both strains grew as healthily as a wild-type strain and had normal telomere length (data not shown), indicating that the tagged proteins were fully functional. Est2p-myc copurified with yPinX1p-TAP on IgG beads, which bind to the ZZ domain in the TAP-tag (Puig et al. 2001), but was not copurified in the control strain that contained the untagged yPinX1p (Fig. 2A), suggesting that the two proteins associate in vivo. To further confirm the interaction between Est2p and yPinX1p, we performed the same experiment in strains with Est2p TAP-tagged and yPinX1p myc-tagged. As with the previous tagged strains, the Est2p-TAP/yPinX1p-myc (yEHB4109) and yPinX1p-myc (yEHB4107) strains had normal growth and telomere length (data not shown). Consistent with the result above, yPinX1p-myc also copurified with Est2p-TAP on IgG beads (Fig. 2B). Taken together, these results suggest that yPinX1p binds, directly or indirectly, to Est2p in vivo.

yPinX1p has previously been shown to be involved in rRNA and snoRNA processing (Guglielmi and Werner 2002). Because telomeres in $\Delta y p i n X 1$ cells were slightly shorter than those in wild-type cells, it was concluded that yPinX1p is not a telomerase inhibitor, unlike its human counterpart (Guglielmi and Werner 2002). However, such slight shortening might have been explained by a pleiotropic effect of the defective processing of rRNA and snoRNA in the deletion strain. We were able to uncouple the effects of yPinX1p on telomere length from its role in snoRNA and rRNA processing. A point mutant, yPinX1p-W38A, does not support cell growth when the wild-type $y P I N X 1$ gene is replaced by it, pre- 

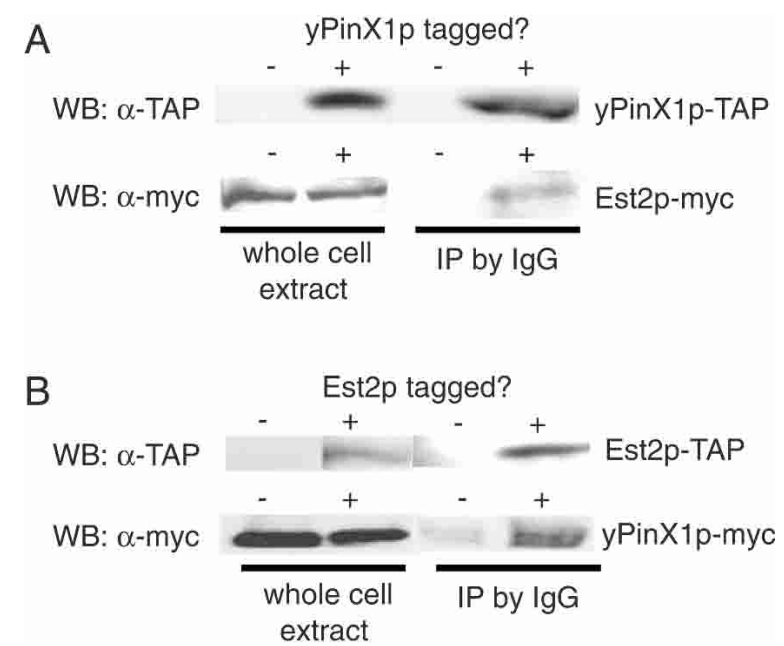

Figure 2. Coimmunoprecipitation of yPinX1p and Est2p. $(A)$ Coimmunoprecipitation of Est2p-myc with yPinX1p-TAP using IgG beads. $(B)$ Coimmunoprecipitation of yPinX1p-myc with Est2p-TAP using IgG beads. For Western blotting (WB), 2\% of the extract used for coimmunoprecipitation experiments was loaded in whole-cell extract lanes.

sumably because of its defects in rRNA and snoRNA processing (data not shown). In agreement with this, mutation of the same amino acid residue to serine, W38S, was reported to be defective in rRNA and snoRNA processing (Guglielmi and Werner 2002). Notably, however, when overexpressed, yPinX1p-W38A was still capable of causing telomere shortening to the same degree as the wild-type yPinX1p. Furthermore, yPinX1p-W38A still copurified with Est2p (Supplemental Fig. S2). Therefore, the functions of yPinXlp in rRNA/snoRNA processing and telomere maintenance are separable.

Est2p associates with $y$ PinX $1 p$ in the absence of TLC1, Est1p, or Est3p

In addition to Est $2 \mathrm{p}$ and TLC1, yeast telomerase holoenzyme contains at least two protein components that are essential for its function in vivo, Estlp and Est3p. Estlp binds to TLC1 and telomeric DNA and is proposed to recruit/activate telomerase at the telomeres (Evans and Lundblad 1999, 2002; Seto et al. 2002; Taggart et al. 2002). Est3p is another component of telomerase holoenzyme whose biochemical function remains unknown (Hughes et al. 2000). We found that the association between Est2p and yPinX1p is not dependent on TLC1, Est1p, or Est3p. This was shown by coimmunoprecipitation experiments in strains singly deleted for each one of these three genes (see Table 1 for strains used in this study). EST2 was cloned into a $2 \mu$ plasmid together with its endogenous promoter and $\mathrm{ADH}$ terminator, and was tagged at its $C$ terminus with $13 \mathrm{myc}$ epitopes. This EST2 plasmid (pRS424Est2myc), together with a plasmid expressing TAP-tagged yPinX1p from the GAL1 promoter (pRS316GalPinX1TAP; see Table 2), was transformed into yeast strain yEHB4084, which is deleted of its endogenous EST2 and maintains its telomeres by the alternative Rad52-dependent recombination pathway (Lundblad and Blackburn 1993). We immunopurified yPinX1p-TAP in two steps with IgG beads and calmodulin beads using the published protocols for TAP-tag purification (Puig et al. 2001) and then performed Western blot analysis to detect Est2pmyc. As with the endogenously expressed tagged Est $2 p$ and $y$ PinX1p, wild-type Est2p-myc overexpressed from the $2 \mu$ plasmid was readily detectable in the purified fractions (Fig. 3A). Furthermore, wild-type Est2p-myc still efficiently copurified with yPinX1p-TAP in TLC1, EST1, or EST3 deletion strains (Fig. 3B). Hence, Est2pmyc associates with yPinX1p independently of TLC1 RNA, Est1p, or Est3p.

The same region in Est2p is required for yPinX1p and for TLC1 binding

The Est2p protein contains six recognizable conserved domains (Fig. 4A) found in other TERTs (Xia et al. 2000). The GQ domain in yeast Est2p is required for its binding to Est3p, another component of the yeast telomerase holoenzyme (Hughes et al. 2000; Friedman

Table 1. Strains used in this study

\begin{tabular}{|c|c|}
\hline Strain & Genotype \\
\hline VY4705 & 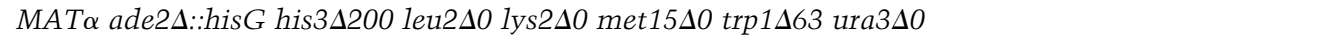 \\
\hline yEHB0234 & 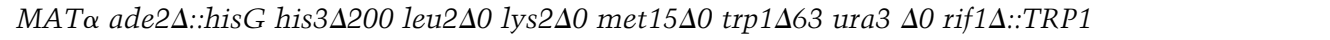 \\
\hline yEHB0235 & 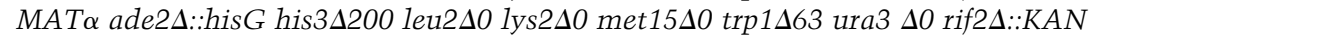 \\
\hline yEHB4008 & 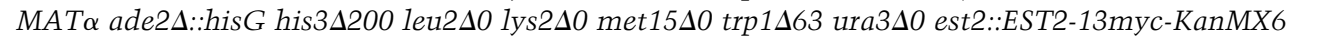 \\
\hline yEHB4084 $4^{\mathrm{a}}$ & 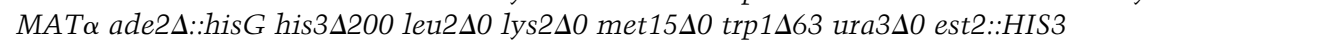 \\
\hline yEHB4100 & 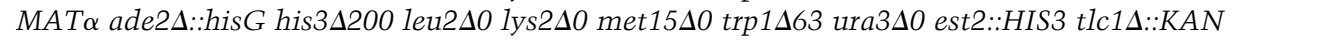 \\
\hline yEHB4104 & 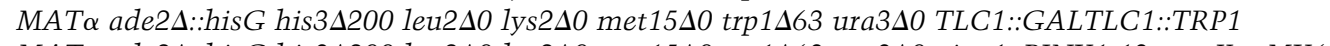 \\
\hline yEHB4107 & 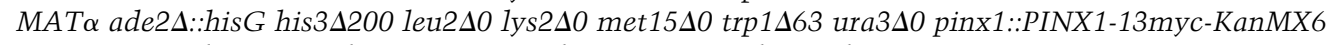 \\
\hline yEHB4109 & 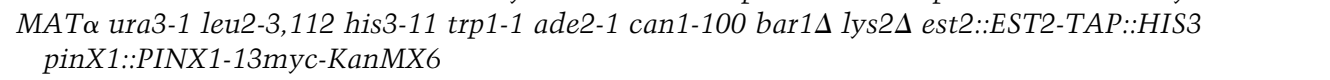 \\
\hline yEHB4114 & 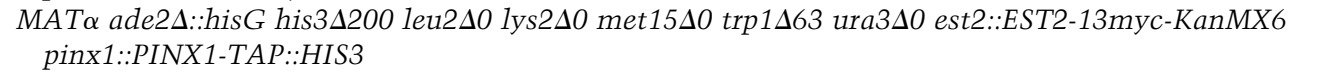 \\
\hline yEHB4120 & 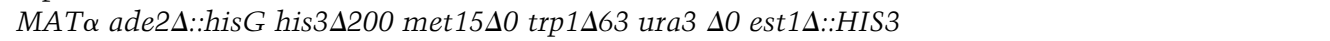 \\
\hline yEHB412 $1^{\mathrm{a}}$ & 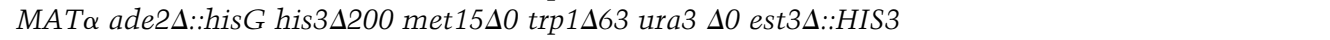 \\
\hline
\end{tabular}

${ }^{a}$ These strains are survivors. 
Table 2. Plasmids used in this study

\begin{tabular}{ll}
\hline Plasmid & \multicolumn{1}{c}{ Description } \\
\hline pRS414GalCyc & GAL1 promoter and CYC terminator cloned into pRS414 \\
pRS414GalPinX1 & PinX1 ORF clones between GAL1 promoter and CYC terminator of pRS414GalCyc \\
pRS316GalPinX1 & GAL1 promoter, PinX1 ORF, and CYC terminator cloned into pRS316 \\
pRS316GalPinX1TAP & GAL1 promoter, PinX1 ORF, TAP tag, and CYC terminator cloned into pRS316 \\
pRS316Est2 & Est2 expressed from its endogenous promoter and terminator, cloned into pRS316 \\
pRS423Est2myc & Est2 tagged with 13-myc at its C terminus, expressed from its endogenous promoter cloned into pRS423 \\
pRS424Est2myc & Est2 tagged with 13-myc at its C terminus, expressed from its endogeous promoter cloned into pRS424 \\
pRS424Est2myc $\Delta \mathrm{N}$ & Same as pRS424Est2myc, except the N domain of Est2 deleted \\
pRS424Est2myc $\Delta \mathrm{GQ}$ & Same as pRS424Est2myc, except the GQ domain of Est2 deleted \\
pRS424Est2myc $\Delta \mathrm{CP}$ & Same as pRS424Est2myc, except the CP domain of Est2 deleted \\
pRS424Est2myc $\Delta \mathrm{QFP}$ & Same as pRS424Est2myc, except the QFP domain of Est2 deleted \\
pRS424Est2myc $\Delta \mathrm{T}$ & Same as pRS424Est2myc, except the T domain of Est2 deleted \\
pRS424Est2myc $\Delta$ RT & Same as pRS424Est2myc, except the RT domain of Est2 deleted \\
\hline
\end{tabular}

et al. 2003). The CP, QFP, and T domains of telomerases are involved in binding to TER in various organisms (Friedman and Cech 1999; Bryan et al. 2000; Armbruster et al. 2001; Lai et al. 2001; Moriarty et al. 2002b). The RT domain shares sequence homology with other reverse transcriptases and contains amino acid residues that directly participate in catalysis (Nakamura et al. 1997). The function of the very $\mathrm{N}$-terminal region is unclear. Deletional and mutational analyses have shown that all six regions are necessary for normal telomerase function (Kelleher et al. 2002).

To determine which region in Est2p is required for its interaction with yPinX1p in vivo, we tested six EST2 mutants, each deleting one single conserved domain as indicated in Figure 4A (see also Table 2). Each EST2 domain mutant was cloned into a $2 \mu$ plasmid with the endogenous EST2 promoter and the $\mathrm{ADH}$ terminator, and tagged with 13-myc epitopes at the $\mathrm{C}$ terminus. Replacement of the wild-type EST2 gene by each mutant EST2 plasmid caused telomere shortening and senescence at the same rate as an EST2 deletion (data not shown). We examined whether each EST2 domain dele-

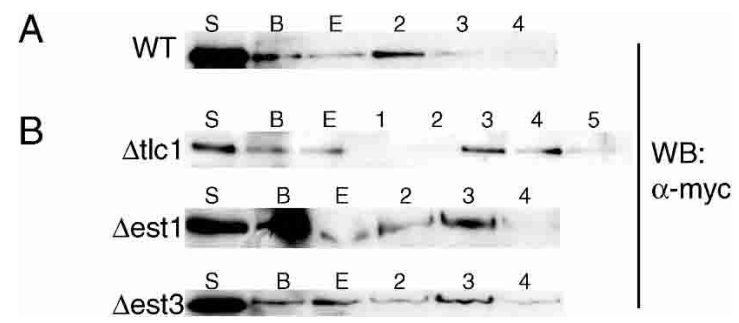

Figure 3. Coimmunoprecipitation of $y P i n X 1 p$ and Est2p is independent of TLC1 RNA, Estlp, or Est3p. (A) Overexpressed Est2p-myc copurified with yPinX1p-TAP in strain yEHB4084 containing wild-type TLC1, EST1, and EST3. Est2p-myc was on a $2 \mu$ plasmid (pRS424Est2-myc), and yPinX1-TAP was expressed from the Gal promoter on plasmid pRS316GalPinX1TAP. (B) Est2p-myc copurified with yPinX1p in $\Delta t 1 c 1, \Delta e s t 1$, or $\Delta$ est3 strains. (S) S100; (B) IgG beads; (E) eluate from IgG beads. Fractions $1-5$ are eluate from calmodulin beads. For Western blotting, $0.2 \%$ of total extract, $2 \%$ of IgG beads after binding, $2 \%$ of IgG beads eluate, and $20 \%$ of calmodulin eluate were loaded. tion mutant protein was stably expressed by Western blot analysis using an anti-myc antibody. Whereas Est $2 \mathrm{p} \Delta \mathrm{N}$-myc was expressed at a lower level than the wild type, the other five mutants were at levels similar to wild type (Fig. 4C).

To determine whether these mutant EST2 proteins could copurify with yPinX1p-TAP, each EST2 domain deletion mutant plasmid was transformed into yeast strain yEHB4084, together with plasmid pRSGALPinX1TAP. We immunopurified yPinX1p-TAP and performed Western blot analysis to detect Est2p-myc. Three of the six mutants- $\triangle \mathrm{CP}, \Delta \mathrm{QFP}$, and $\Delta \mathrm{T}-$ which delete the central region of Est2p, failed to copurify with yPinX1pTAP (Fig. 4B), whereas the other three mutants $-\Delta N$, $\Delta \mathrm{GQ}$, and $\Delta \mathrm{RT}$ - still copurified with yPinX1p-TAP (Fig. 4B). Thus, the central region of Est $2 p$ encompassing the $\mathrm{CP}, \mathrm{QFP}$, and $\mathrm{T}$ domains is required for yPinX1p association. Interestingly, immunoprecipitated $\triangle \mathrm{CP}, \triangle \mathrm{QFP}$, and $\Delta \mathrm{T}$ mutant proteins also failed to pull down TLC1 RNA, in contrast to the other three mutants (Fig. 4C). This result is consistent with previous studies of human and Tetrahymena TERT proteins, where deletion or mutation of the $\mathrm{CP}, \mathrm{QFP}$, and $\mathrm{T}$ domains each reduced or abolished TER binding (Armbruster et al. 2001; Lai et al. 2001; Moriarty et al. 2002b). Thus, the regions in Est2p necessary for either TLC1 or yPinX1p binding overlap.

\section{Two distinct Est2 complexes contain either TLC1 or yPinX1}

The above results showed that association of Est2p with yPinX1p or TLC1 required the same Est2p region. To determine whether these three molecules are in the same or different complexes, we fractionated telomerase using the previously reported DEAE chromatography method (Prescott and Blackburn 1997a,b) from a yeast strain expressing wild-type Est $2 p$-myc from a $2 \mu$ plasmid and yPinX1p-myc from its endogenous chromosomal locus. Cells were lysed, and the S100 extract was loaded onto a DEAE column. As shown by Northern blot analysis, the vast majority of TLC1 bound to the column, with no TLC1 detected in the flowthrough (Fig. 5A). However, 


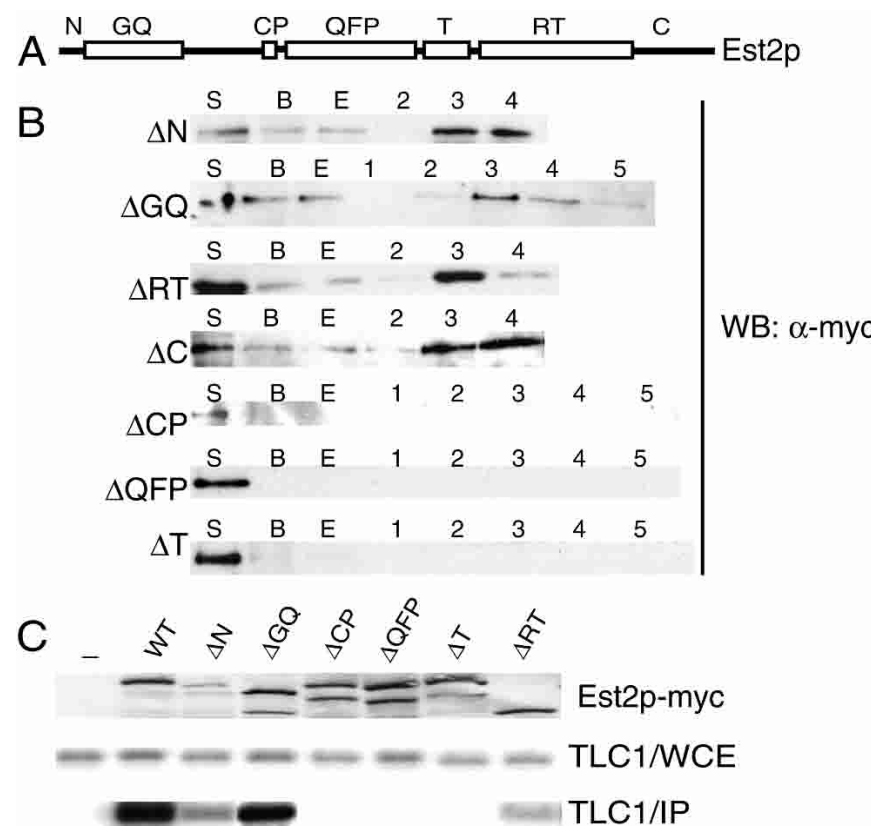

Figure 4. The same region in Est2p is required for both yPinX1p and TLC1 binding. (A) Diagram of Est2p domain structures. $(B)$ Est2p mutant proteins deleted of domain N, GQ, RT, or $\mathrm{C}$ copurify with yPinX1p. Est2p mutant proteins deleted of domain CP, QFP, or T do not copurify with yPinX1p. (S) S100; (B) IgG beads; (E) eluate from IgG beads. Fractions $1-5$ are eluate from calmodulin beads. For Western blotting, $0.2 \%$ of total extract, $2 \%$ of IgG beads after binding, $2 \%$ of IgG beads eluate, and $20 \%$ of calmodulin eluate were loaded. (C) Est2p mutant proteins deleted of domain CP, QFP, or T do not bind TLC1. (Top panel) Western blotting of Est2p domain deletion mutants. (Lower panel) Northern blotting of TLC1 RNA. (WCE) RNA prepared from whole-cell extracts; (IP) RNA prepared from cell extracts immunoprecipitated with anti-myc antibody 9E10. For RNA preparation, $10 \%$ of input whole-cell extract was used and was loaded in WCE lanes.

Western blot analysis showed that a significant portion of Est2p was in this flowthrough (Fig. 5A), suggesting that a fraction of Est2p is TLC1-free. TLC1 was eluted, and its concentration peaked in fraction 5 (Fig. 5A). Est $2 p$ protein copurified with these TLC1 fractions, with the peak fraction of Est2p coinciding with the TLC1 peak (Fig. 5A). As previously reported, these fractions contained active telomerase complex (Prescott and Blackburn 1997a,b). Notably, no yPinX1p was detectable in these fractions (Fig. 5A, bottom panel). Therefore, active telomerase complex containing Est2p and TLC1 RNA does not contain detectable levels of yPinX1p.

Next, we used an independent method to test whether TLC1 RNA is present in the yPinX1p-Est2p complex. TAP-tagged yPinX1p was purified from yeast using IgG beads as described above. As shown above, Est2p-myc was found to copurify with yPinX1p (Fig. 5B, bottom left panel). However, no TLC1 was detected in the yPinX1pTAP pull-down (Fig. 5B, top left panel). As a positive control, the same extract was immunoprecipitated with anti-myc antibody to pull down Est2p-myc, and TLC1 RNA was readily detected (Fig. 5B, right panels). Taken together, these results show that there are at least two distinct Est $2 p$ complexes: the enzymatically active telomerase containing Est2p and TLC1 (possibly with other proteins), which does not contain yPinX1p; and an inactive complex containing Est2p-yPinX1p, but not TLC1 RNA.

Evidence that active telomerase is a dimer with two active sites and two interacting RNAs has been reported previously (Prescott and Blackburn 1997a; Beattie et al. 2001; Wenz et al. 2001; Ly et al. 2003). In human telomerase, TERT itself is known to interact via TERTTERT protein-protein binding in vitro (Arai et al. 2002). Using coimmunoprecipitation experiments with cells expressing HA-tagged Est2p from one allele and myctagged Est $2 p$ from the other allele, we found that Est $2 p-$ Est $2 p$ in vivo association could still occur even in strains in which the other essential telomerase holoenzyme components Est1p, Est3p, or the telomerase RNA gene (TLC1) were deleted (Supplemental Fig. S3). This property of independence from other telomerase holoenzyme components was shared by the Est2p-yPinX1p association described above. Therefore, we delineated the domains of Est $2 p$ that are required for this Est $2 p-E s t 2 p$ interaction in vivo, by coexpressing the wild-type Est $2 p$ (tagged with $13 \times \mathrm{myc}$ ) and each of the Est $2 \mathrm{p}$ single-domain deletion mutants (tagged with $3 \times \mathrm{HA}$ ), both from the endogenous promoter on $2 \mu$ plasmids. Deletion of the T or RT domain, but not of the CP or QFP domains, significantly disrupted the in vivo physical association between Est2p molecules (Supplemental Fig. S4). Hence the region(s) of Est $2 p$ required for its physical Est $2 p-$ Est $2 p$ interaction in vivo overlaps with, but is not identical to, the common region required for the mutually exclusive PinX1p or TLC1 binding. These results suggest the possibility that yPinxlp binding may also interfere with telomerase dimerization.

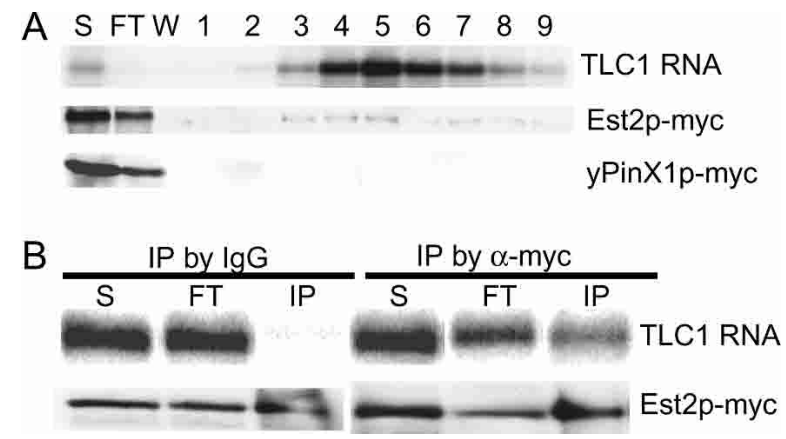

Figure 5. Detection of two distinct Est2p complexes: Est2pTLC1 and Est2p-yPinX1p. (A) DEAE purified fractions contain TLC1 and Est2p, but no detectable yPinX1p. (S) S100 extract; (FT) flowthrough from DEAE column; (W) last wash from DEAE column; (\#1-9) DEAE eluted fractions. (B) yPinX1p-TAP complex purified with IgG contained Est2p, but not TLC1. (S) S100 extract; (FT) flowthrough from IgG beads; (IP) immunoprecipitated samples. (Top panel) Northern blot analysis probed for TLC1 RNA. (Bottom panel) Western blot analysis probed for Est2p-myc. For Western blot analysis and preparation of RNA for Northern blot analysis, 10\% of the input extract was used. 


\section{TLC1 levels influence yPinX1-Est2p binding efficiency}

The above results showed that Est2p exists in alternative complexes, containing either yPinX1p or TLC1 RNA. The overlap of the Est $2 p$ regions required for binding of PinX1p or TLC1 further suggested that PinX1p and TLC1 may compete for Est2p. Therefore, we tested whether TLC1 RNA levels influence the level of the yPinX1-Est2p complex. We determined the effects of TLC1 deletion or overexpression on the extent of coimmunoprecipitation of Est2p-myc with yPinX1p-TAP. TAP-tagged yPinX1p was expressed from a GAL1 promoter in strains containing either wild-type TLC1, TLC1 deletion $(\Delta t l c 1)$, or TLC1 overexpressed from a GAL1 promoter. Compared with the wild-type TLC1 strain, the total level of Est2p-myc protein slightly increased in the TLC1 overexpression strain, and reproducibly decreased dramatically in the $\Delta t l c 1$ strain (Fig. 6A). Strikingly, despite this lower level of total Est2p-myc, in the $\Delta t 1 c 1$ strain more Est2p-myc was reproducibly coimmunoprecipitated by yPinX1p-TAP than in the control TLC1 wild-type strain (Fig. 6A). In contrast, in the TLC1 over-
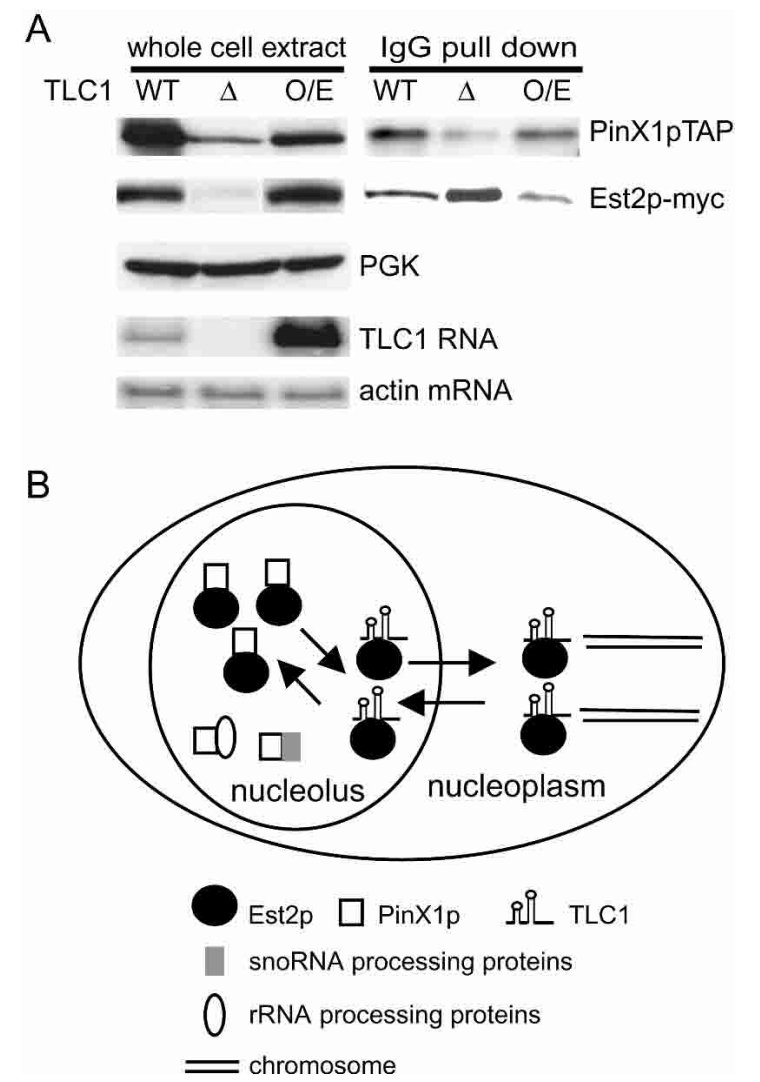

Figure 6. TLC1 levels influence yPinX1-Est2p binding efficiency. (A) Deletion of TLC1 results in more Est2p associated with yPinX1p, and overexpression of TLC1 results in less Est2p associated with yPinX1p. (O/E) TLC1 overexpressed from the GAL1 promoter. PGK serves as the loading control for Western blotting. The amount of TLC1 RNA is shown on the bottom with actin mRNA as the loading control. $(B)$ A model for yPinX1p-mediated inhibition of telomerase activity. See text for description. expression strain, lower amounts of Est2p-myc were coimmunoprecipitated by yPinX1p-TAP. In summary, these results strongly support the predictions of our model that yPinX1p and TLC1 RNA compete for Est2p binding.

\section{Discussion}

The results of this study support a novel mechanism for telomerase activity regulation. Our results show that Est2p forms two distinct complexes: the active telomerase enzyme containing TLC1, and an alternative complex containing yPinX1p but no TLC1. Furthermore, we have provided evidence that yPinX1p competes with TLC1 for Est2p binding in vivo. Thus, we propose that $y$ PinX1p sequesters Est2p to prevent assembly of Est $2 p$ and TLC1 RNA into the enzymatically active telomerase RNP (Fig. 6B).

\section{PinX1p: a dual-function protein}

yPinX $1 p$ is an essential nucleolar protein required for the processing of rRNA and some snoRNAs (Guglielmi and Werner 2002). The poor growth in yPINX1 deletion cells is very likely caused by an inability to process rRNA and snoRNAs. The rRNA and snoRNA processing functions of PinX1p are conserved as the human PINX1 gene complemented the slow growth and rRNA maturation defects of the yeast deletion strain (Guglielmi and Werner 2002).

Because telomeres in $\Delta y p i n X 1$ cells were slightly shorter than in wild-type cells, a previous report concluded that $y$ PinX1p is not a telomerase inhibitor, unlike its human counterpart (Guglielmi and Werner 2002). However, such slight shortening might have been explained by a pleiotropic effect of the defective processing of rRNA and snoRNA in the deletion strain. In agreement with this, two yPinX1p mutants (W38S and $\Delta 1-$ 24) that caused slight shortening of telomeres are both defective for rRNA processing; whereas another mutant $(\Delta 150-271)$ that retained rRNA/snoRNA functions, had wild-type telomere length (Guglielmi and Werner 2002). Furthermore, as described above (see Results and Supplemental Fig. 2S), the functions of yPinX1p in rRNA/ snoRNA processing and telomere maintenance are separable. We have shown here that yeast PinX1p binds to $\mathrm{CP}, \mathrm{QFP}$, and $\mathrm{T}$ regions of telomerase catalytic protein Est $2 \mathrm{p}$. Because these regions are conserved among all telomerase catalytic subunits of all species, a similar mechanism may exist for human Pinxlp-TERT binding. In support of a conserved role for PinX1-mediated telomerase regulation, we overexpressed human PinX1p in yeast and observed decreased telomere length (data not shown). Thus, we propose that yeast pinX1p, like its human counterpart, is also a dual-function protein involved in both rRNA/snoRNA processing and telomerase regulation.

\section{Role of the nucleolus in telomerase activity}

This proposed sequestration of telomerase into alternative complexes may, at least in part, underlie the trans- 
location between different subcellular compartments that has been suggested as a mechanism of regulating telomerase activity. The nucleolar localization of hTERT can be influenced by transformation with a viral oncogene or DNA damage (Wong et al. 2002). However, no protein factors involved in such movement of telomerase have been identified. In addition, in human T-cells and smooth muscle cells, hTERT is imported from the cytoplasm to the nucleus upon growth factor stimulation (Liu et al. 2001). The 14-3-3 signaling proteins have been shown to interact with hTERT and prevent its nuclear export. This suggested that $14-3-3$ proteins are required for the nuclear accumulation of hTERT, and may thus be involved in another level of regulation of in vivo telomerase activity (Seimiya et al. 2000).

The nucleolus has been strongly implicated in the biogenesis of telomerase and regulation of its activity. Mammalian telomerase RNA shares domains with small nucleolar RNAs that bind to several known nucleolar proteins (Mitchell et al. 1999; Pogacic et al. 2000; Fu and Collins 2003). Recently, movement of hTERT between subnuclear compartments has been reported. hTERT in primary cells was shown in culture to localize in the nucleolus, but is apparently released into the nucleoplasm during the late $S / G_{2}$ stages of the cell cycle, coincident with the replication of telomeres (Wong et al. 2002). In contrast, in transformed cells, hTERT has a diffuse nucleoplasmic distribution (Wong et al. 2002). In $S$. cerevisiae, overexpressed Est2p accumulated in the nucleolus but was found throughout the nucleus upon TLC1 overexpression (Teixeira et al. 2002). This redistribution of overexpressed Est $2 p$ correlated with increased in vitro telomerase activity, consistent with the interpretation that enzymatically active telomerase is in the nucleoplasm outside the nucleolus (Teixeira et al. 2002).

Under what physiological situations might PinX1p act to regulate telomerase activity? PinX1p, like overexpressed Est2p, is predominantly a nucleolar protein, but is also found in the nucleoplasm (Zhou and Lu 2001; Teixeira et al. 2002). Interestingly, the nucleolar localization domain of hTERT maps to amino acids 326-620 (Etheridge et al. 2002). The homologous region in Est2p includes the yPinX1p-interacting region we have reported here. We therefore propose that PinX1p is involved in controlling the movement of TERT between nucleolus and nucleoplasm. In support of this model, human telomerase is found in the nucleoplasm at the time during the cell cycle when telomeres are replicated, and also upon transformation, which promotes cell cycling. In addition, telomerase enzymatic activity detectable in cell extracts is very rapidly up-regulated in human leukemia HL-60 cells treated with clinical doses of the DNA-damaging drug etoposide (Moriarty et al. 2002a). In S. cerevisiae, the level of yPINX1 mRNA decreases significantly upon DNA damage or general environmental stress (Gasch et al. 2000, 2001). We suggest that this increases Est2p levels in the enzymatically active complex under these conditions.

In summary, the results reported here, together with the above findings, suggest that release of Est2p from its sequestering PinX1p, to allow binding of telomerase RNA, may constitute an efficient and responsive mechanism to rapidly regulate telomerase.

\section{Materials and methods}

\section{Southern blot analysis of telomeres}

Cells were streaked on plates selective for the plasmids as specified. Genomic DNA was prepared and digested with XhoI and run on $0.8 \%$ agarose gels. DNA was transferred from gels to Hybond $\mathrm{N}^{+}$membranes (Amersham) and probed with a $\gamma^{-{ }^{32}} \mathrm{P}$ end-labeled wild-type telomeric repeat oligonucleotide as described previously (Prescott and Blackburn 1997b).

\section{Immunoprecipitation and Western blot analysis}

Cells were grown in selective media to an $\mathrm{OD}_{600}$ of $0.5-0.6$, lysed with glass beads in IPP150 buffer (25 mM HEPES, $150 \mathrm{mM}$ $\mathrm{NaCl}, 1$ mM EDTA, 1 mM EGTA, 0.1\% NP-40, 10\% glycerol, 1 $\mathrm{mM}$ DTT, and protease inhibitors). The lysates were centrifuged at $13,000 \mathrm{rpm}$ for $15 \mathrm{~min}$ and $40,000 \mathrm{rpm}$ for $30 \mathrm{~min}$ to obtain the extracts. Typically, $2-3 \mathrm{mg}$ of total protein was immunoprecipitated with anti-myc antibody 9E10 (Covance) and protein A beads (Sigma) in a 400- $\mu \mathrm{L}$ total volume for $4 \mathrm{~h}$, washed with IPP150, and resuspended in SDS sample buffer. Immunoprecipitation of TAP-tagged proteins was performed as reported using 100-150 mg of total protein (Puig et al. 2001). Briefly, extracts were incubated with IgG beads for $2 \mathrm{~h}$ at $4^{\circ} \mathrm{C}$, and the beads were washed with IPP150 buffer and resuspended in TEVcleavage buffer $(25 \mathrm{mM}$ HEPES, $150 \mathrm{mM} \mathrm{NaCl}, 0.5 \mathrm{mM}$ EDTA, $1 \mathrm{mM}$ EGTA, $0.1 \%$ NP-40, 10\% glycerol, $1 \mathrm{mM} \mathrm{DTT)}$. TEV protease (Invitrogen) was added, and the sample was rotated overnight at $4^{\circ} \mathrm{C}$. Eluate was collected from the TEV-cleaved beads. Three volumes of calmodulin binding buffer $(10 \mathrm{mM}$ $\beta$-mercaptoethanol, $25 \mathrm{mM}$ HEPES, $150 \mathrm{mM} \mathrm{NaCl}, 1 \mathrm{mM} \mathrm{Mg}$ acetate, $1 \mathrm{mM}$ imidazole, $2 \mathrm{mM} \mathrm{CaCl}_{2}, 0.1 \% \mathrm{NP}-40,10 \%$ glycerol), and calmodulin beads (Stratagene) were added, and the eluate was rotated for $1 \mathrm{~h}$ at $4^{\circ} \mathrm{C}$. The calmodulin beads were washed with CBP binding buffer and eluted with calmodulin elution buffer (10 mM $\beta$-mercaptoethanol, $25 \mathrm{mM}$ HEPES, 150 $\mathrm{mM} \mathrm{NaCl}, 1 \mathrm{mM} \mathrm{Mg}$-acetate, $1 \mathrm{mM}$ imidazole, $2 \mathrm{mM}$ EGTA, $0.1 \%$ NP- $40,10 \%$ glycerol). Typically, $0.2 \%$ of total extract, $2 \%$ of IgG beads after binding, $2 \%$ of IgG beads eluate, and $20 \%$ of calmodulin elute were loaded for Western blotting, except in Figures 2 and 5 , where $2 \%$ and $3 \%$ of the extract used for coimmunoprecipitation experiments were loaded in whole-cell extract lanes for Western blotting.

For Western blot analysis, peroxidase-anti-peroxidase (Sigma) antibody was used to detect TAP tag, and anti-myc clone 9E10 was used to detect myc tag. The same membrane was probed for PGK using anti-PGK antibody (Molecular Probes) as the loading control.

\section{Northern blot analysis}

RNA was extracted from total protein lysates, or from immunoprecipitated samples with phenol/chloroform and treated with glyoxal (Sigma). RNA was run on $1.3 \%$ agarose gels, transferred to Hybond-NX membrane (Amersham) and hybridized with probes made by random primers (RediPrime II; Amersham). Signals were quantified with PhosphorImager (Storm 860; Molecular Dynamics). The same membrane was probed for actin mRNA as the loading control. 


\section{DEAE fractionation and in vitro telomerase activity assay}

DEAE fractionation was performed as described (Prescott and Blackburn 1997b). RNA was prepared from total extract, flowthrough, the last wash, and each fraction for Northern blot analysis. Western blot analysis was performed with the same samples.

In vitro telomerase activity assay was performed as described (Prescott and Blackburn 1997b). Wild-type yeast cells (BY4705) were transformed with either the vector control plasmid or the yPinX1p overexpression plasmid. Cells were grown in galactose medium to induce yPinX1p overexpression. S100 extraction and DEAE fractionation were carried out as described. To normalize, peak DEAE fractions from the vector control and yPinX1p plasmids containing the same amount of TLC1 were used for quantitative comparison.

\section{Acknowledgments}

We thank Shivani Nautiyal for yeast strains yEHB4120 and yEHB4121, and Chris Smith for strains yEHB0234 and yEHB0235. We thank Dan Levy, Tanya Williams, and Jeff Seidel for critical reading of the manuscript. This work was supported by NIH grant GM26259 to E.H.B. and a University of California San Francisco Herbert Boyer Postdoctoral Fellowship to J.L.

The publication costs of this article were defrayed in part by payment of page charges. This article must therefore be hereby marked "advertisement" in accordance with 18 USC section 1734 solely to indicate this fact.

\section{References}

Arai, K., Masutomi, K., Khurts, S., Kaneko, S., Kobayashi, K., and Murakami, S. 2002. Two independent regions of human telomerase reverse transcriptase are important for its oligomerization and telomerase activity. J. Biol. Chem. 277: $8538-8544$.

Armbruster, B.N., Banik, S.S., Guo, C., Smith, A.C., and Counter, C.M. 2001. N-terminal domains of the human telomerase catalytic subunit required for enzyme activity in vivo. Mol. Cell. Biol. 21: 7775-7786.

Baldwin Jr., A.S. 1996. The NF-кB and ІкB proteins: New discoveries and insights. Annu. Rev. Immunol. 14: 649-683.

Beattie, T.L., Zhou, W., Robinson, M.O., and Harrington, L. 1998. Reconstitution of human telomerase activity in vitro. Curr. Biol. 8: 177-180.

- 2001. Functional multimerization of the human telomerase reverse transcriptase. Mol. Cell. Biol. 21: 6151-6160.

Blackburn, E.H. 2000. Telomeres and telomerase. Keio J. Med. 49: 59-65.

Blasco, M.A. 2002. Telomerase beyond telomeres. Nat. Rev. Cancer 2: 627-633.

Blasco, M.A. and Hahn, W.C. 2003. Evolving views of telomerase and cancer. Trends Cell Biol. 13: 289-294.

Bryan, T.M., Goodrich, K.J., and Cech, T.R. 2000. Telomerase RNA bound by protein motifs specific to telomerase reverse transcriptase. Mol. Cell 6: 493-499.

Cohn, M. and Blackburn, E.H. 1995. Telomerase in yeast. Science 269: 396-400.

Concannon, C.G., Orrenius, S., and Samali, A. 2001. Hsp27 inhibits cytochrome $c$-mediated caspase activation by sequestering both pro-caspase-3 and cytochrome c. Gene Expr. 9: 195-201.

Diede, S.J. and Gottschling, D.E. 1999. Telomerase-mediated telomere addition in vivo requires DNA primase and DNA polymerases $\alpha$ and $\delta$. Cell 99: 723-733.

Etheridge, K.T., Banik, S.S., Armbruster, B.N., Zhu, Y., Terns, R.M., Terns, M.P., and Counter, C.M. 2002. The nucleolar localization domain of the catalytic subunit of human telomerase. J. Biol. Chem. 277: 24764-24770.

Evans, S.K. and Lundblad, V. 1999. Est1 and Cdc13 as comediators of telomerase access. Science 286: 117-120.

. 2002. The Est1 subunit of Saccharomyces cerevisiae telomerase makes multiple contributions to telomere length maintenance. Genetics 162: 1101-1115.

Friedman, K.L., and Cech, T.R. 1999. Essential functions of amino-terminal domains in the yeast telomerase catalytic subunit revealed by selection for viable mutants. Genes \& Dev. 13: 2863-2874.

Friedman, K.L., Heit, J.J., Long, D.M., and Cech, T.R. 2003. Nterminal domain of yeast telomerase reverse transcriptase: Recruitment of Est3p to the telomerase complex. Mol. Biol. Cell 14: 1-13.

$\mathrm{Fu}, \mathrm{D}$. and Collins, K. 2003. Distinct biogenesis pathways for human telomerase RNA and H/ACA small nucleolar RNAs. Mol. Cell 11: 1361-1372.

Gasch, A.P., Spellman, P.T., Kao, C.M., Carmel-Harel, O., Eisen, M.B., Storz, G., Botstein, D., and Brown, P.O. 2000. Genomic expression programs in the response of yeast cells to environmental changes. Mol. Biol. Cell 11: 4241-4257.

Gasch, A.P., Huang, M., Metzner, S., Botstein, D., Elledge, S.J., and Brown, P.O. 2001. Genomic expression responses to DNA-damaging agents and the regulatory role of the yeast ATR homolog Mec1p. Mol. Biol. Cell 12: 2987-3003.

Ghosh, S., May, M.J., and Kopp, E.B. 1998. NF-кB and Rel proteins: Evolutionarily conserved mediators of immune responses. Annu. Rev. Immunol. 16: 225-260.

Greene, E.C. and Shippen, D.E. 1998. Developmentally programmed assembly of higher order telomerase complexes with distinct biochemical and structural properties. Genes \& Dev. 12: 2921-2931.

Guglielmi, B. and Werner, M. 2002. The yeast homolog of human PinX1 is involved in rRNA and small nucleolar RNA maturation, not in telomere elongation inhibition. J. Biol. Chem. 277: 35712-35719.

Hardy, C.F., Sussel, L., and Shore, D. 1992. A RAP1-interacting protein involved in transcriptional silencing and telomere length regulation. Genes \& Dev. 6: 801-814.

Hornig, N.C., Knowles, P.P., McDonald, N.Q., and Uhlmann, F. 2002. The dual mechanism of separase regulation by securin. Curr. Biol. 12: 973-982.

Hughes, T.R., Evans, S.K., Weilbaecher, R.G., and Lundblad, V. 2000. The Est3 protein is a subunit of yeast telomerase. Curr. Biol. 10: 809-812.

Karamysheva, Z., Wang, L., Shrode, T., Bednenko, J., Hurley, L.A., and Shippen, D.E. 2003. Developmentally programmed gene elimination in Euplotes crassus facilitates a switch in the telomerase catalytic subunit. Cell 113: 565-576.

Kelleher, C., Teixeira, M.T., Forstemann, K., and Lingner, J. 2002. Telomerase: Biochemical considerations for enzyme and substrate. Trends Biochem. Sci. 27: 572-579.

Lai, C.K., Mitchell, J.R., and Collins, K. 2001. RNA binding domain of telomerase reverse transcriptase. Mol. Cell. Biol. 21: 990-1000.

Licht, J.D. and Collins, K. 1999. Telomerase RNA function in recombinant Tetrahymena telomerase. Genes \& Dev. 13: $1116-1125$.

Liu, K., Hodes, R.J., and Weng, N. 2001. Cutting edge: Telomerase activation in human $\mathrm{T}$ lymphocytes does not require increase in telomerase reverse transcriptase (hTERT) protein 
but is associated with hTERT phosphorylation and nuclear translocation. J. Immunol. 166: 4826-4830.

Loayza, D. and De Lange, T. 2003. POT1 as a terminal transducer of TRF1 telomere length control. Nature 424: 10131018.

Lundblad, V. and Blackburn, E.H. 1993. An alternative pathway for yeast telomere maintenance rescues est $1^{-}$senescence. Cell 73: 347-360.

Ly, H., Xu, L., Rivera, M.A., Parslow, T.G., and Blackburn, E.H. 2003. A role for a novel 'trans-pseudoknot' RNA-RNA interaction in the functional dimerization of human telomerase. Genes \& Dev. 17: 1078-1083.

Marcand, S., Wotton, D., Gilson, E., and Shore, D. 1997. Raplp and telomere length regulation in yeast. Ciba Found. Symp. 211: 76-103.

Marcand, S., Brevet, V., Mann, C., and Gilson, E. 2000. Cell cycle restriction of telomere elongation. Curr. Biol. 10: 487490.

Mitchell, J.R., Cheng, J., and Collins, K. 1999. A box H/ACA small nucleolar RNA-like domain at the human telomerase RNA 3' end. Mol. Cell. Biol. 19: 567-576.

Moriarty, T.J., Dupuis, S., and Autexier, C. 2002a. Rapid upregulation of telomerase activity in human leukemia HL-60 cells treated with clinical doses of the DNA-damaging drug etoposide. Leukemia 16: 1112-1120.

Moriarty, T.J., Huard, S., Dupuis, S., and Autexier, C. $2002 \mathrm{~b}$. Functional multimerization of human telomerase requires an RNA interaction domain in the $\mathrm{N}$ terminus of the catalytic subunit. Mol. Cell. Biol. 22: 1253-1265.

Nakamura, T.M., Morin, G.B., Chapman, K.B., Weinrich, S.L., Andrews, W.H., Lingner, J., Harley, C.B., and Cech, T.R. 1997. Telomerase catalytic subunit homologs from fission yeast and human. Science 277: 955-959.

Pogacic, V., Dragon, F., and Filipowicz, W. 2000. Human H/ACA small nucleolar RNPs and telomerase share evolutionarily conserved proteins NHP2 and NOP10. Mol. Cell. Biol. 20: 9028-9040.

Prescott, J. and Blackburn, E.H. 1997a. Functionally interacting telomerase RNAs in the yeast telomerase complex. Genes \& Dev. 11: 2790-2800.

- 1997b. Telomerase RNA mutations in Saccharomyces cerevisiae alter telomerase action and reveal nonprocessivity in vivo and in vitro. Genes \& Dev. 11: 528-540.

Puig, O., Caspary, F., Rigaut, G., Rutz, B., Bouveret, E., BragadoNilsson, E., Wilm, M., and Seraphin, B. 2001. The tandem affinity purification (TAP) method: A general procedure of protein complex purification. Methods 24: 218-229.

Seimiya, H., Sawada, H., Muramatsu, Y., Shimizu, M., Ohko, K., Yamane, K., and Tsuruo, T. 2000. Involvement of 14-3-3 proteins in nuclear localization of telomerase. $E M B O J$. 19: 2652-2661.

Seto, A.G., Livengood, A.J., Tzfati, Y., Blackburn, E.H., and Cech, T.R. 2002. A bulged stem tethers Estlp to telomerase RNA in budding yeast. Genes \& Dev. 16: 2800-2812.

Taggart, A.K. and Zakian, V.A. 2003. Telomerase: What are the Est proteins doing? Curr. Opin. Cell Biol. 15: 275-280.

Taggart, A.K., Teng, S.C., and Zakian, V.A. 2002. Estlp as a cell cycle-regulated activator of telomere-bound telomerase. Science 297: 1023-1026.

Teixeira, M.T., Forstemann, K., Gasser, S.M., and Lingner, J. 2002. Intracellular trafficking of yeast telomerase components. EMBO Rep. 3: 652-659.

Waizenegger, I., Gimenez-Abian, J.F., Wernic, D., and Peters, J.M. 2002. Regulation of human separase by securin binding and autocleavage. Curr. Biol. 12: 1368-1378.

Weinrich, S.L., Pruzan, R., Ma, L., Ouellette, M., Tesmer, V.M.,
Holt, S.E., Bodnar, A.G., Lichtsteiner, S., Kim, N.W., Trager, J.B., et al. 1997. Reconstitution of human telomerase with the template RNA component hTR and the catalytic protein subunit hTRT. Nat Genet 17: 498-502.

Wenz, C., Enenkel, B., Amacker, M., Kelleher, C., Damm, K., and Lingner, J. 2001. Human telomerase contains two cooperating telomerase RNA molecules. EMBO J. 20: 3526-3534.

Wong, J.M., Kusdra, L., and Collins, K. 2002. Subnuclear shuttling of human telomerase induced by transformation and DNA damage. Nat. Cell Biol. 4: 731-736.

Wotton, D. and Shore, D. 1997. A novel Raplp-interacting factor, Rif2p, cooperates with Riflp to regulate telomere length in Saccharomyces cerevisiae. Genes \& Dev. 11: 748-760.

Xia, J., Peng, Y., Mian, I.S., and Lue, N.F. 2000. Identification of functionally important domains in the $\mathrm{N}$-terminal region of telomerase reverse transcriptase. Mol. Cell. Biol. 20: 51965207.

Zhou, X.Z. and Lu, K.P. 2001. The Pin2/TRF1-interacting protein PinX1 is a potent telomerase inhibitor. Cell 107: $347-$ 359. 


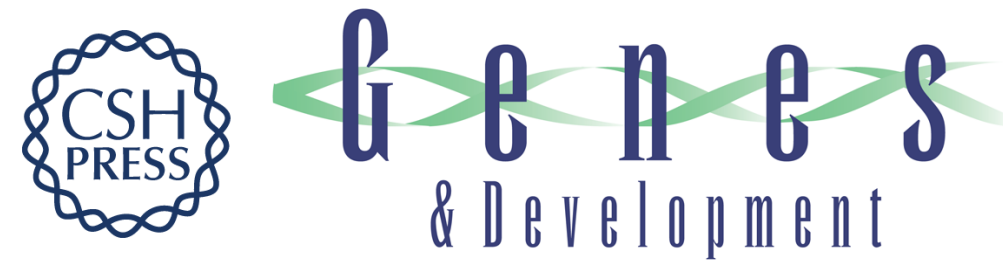

\section{Nucleolar protein PinX1p regulates telomerase by sequestering its protein catalytic subunit in an inactive complex lacking telomerase RNA}

Jue Lin and Elizabeth $\mathrm{H}$. Blackburn

Genes Dev. 2004, 18:

Access the most recent version at doi:10.1101/gad.1171804

Supplemental http://genesdev.cshlp.org/content/suppl/2004/02/20/1171804.DC1

Material

References This article cites 55 articles, 29 of which can be accessed free at: http://genesdev.cshlp.org/content/18/4/387.full.html\#ref-list-1

License

Email Alerting Receive free email alerts when new articles cite this article - sign up in the box at the top Service right corner of the article or click here.

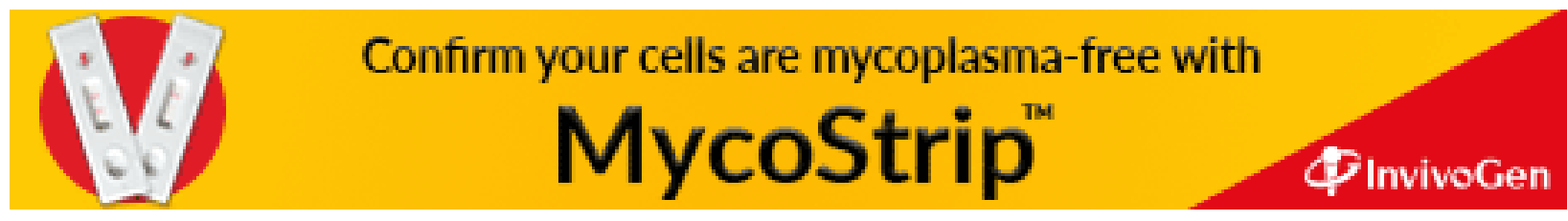

